\title{
Methodology for assessment of the accessibility of a brown coal deposit with Analytical Hierarchy Process and Weighted Linear Combination
}

\author{
Jan Blachowski ${ }^{1}$
}

Received: 5 March 2014/ Accepted: 24 April 2015/Published online: 5 May 2015

(C) The Author(s) 2015. This article is published with open access at Springerlink.com

\begin{abstract}
The research aimed to assess the accessibility of a brown coal deposit for development with respect to environmental and land use functions of the terrain. A combination of the Analytical Hierarchy Process (AHP) and the Weighted Linear Combination methodology was proposed to determine weights of environmental and spatial (land use) factors conditioning development of an open-cast mine project and to produce a composite accessibility map in a geographic information system (GIS). The environmental and spatial factors (criteria) were identified in a survey of a group of experts, and the weights were determined by pairwise comparison of criteria by the same group of experts. The following ones were identified as the most significant factors constraining development of a brown coal open-cast mining project: nature protection areas, cultural and historical monuments, populated areas, underground water reservoirs and surface waters. The research was done on a case study of the Legnica brown coal deposit located in the Dolnoslaskie Province in SW Poland. The identified criteria were mapped and standardized in GIS. The final composite map was obtained in the result of a weighted map overlay analysis with the weights determined in the result of AHP analysis. The results, presented graphically and statistically, show that the western area of the three analysed Legnica deposit coal fields is the least inaccessible with respect to the analysed criteria and that the northern one is the most inaccessible. The results can
\end{abstract}

Jan Blachowski

jan.blachowski@pwr.edu.pl

1 Faculty of Geoengineering, Mining and Geology, Wroclaw University of Technology, Wyb. Wyspianskiego 27, 50-370 Wroclaw, Poland be used to support sustainable spatial policy and development on all levels of public administration.

Keywords AHP - WLC · GIS - Brown coal - Deposit . Accessibility
Abbreviations
AHP Analytical Hierarchy Process
CI Consistency Index
CR Consistency Ratio
GIS Geographic information system
MCA Multicriteria analysis
MCE Multicriteria evaluation
OWA Ordered Weighted Averaging
RI Random index
WLC Weighted linear combination

\section{Introduction}

Assessment of the accessibility of a particular mineral resource deposit for development requires consideration and evaluation of numerous, known, factors, included among these being geological and mining conditions, resource quality, environmental and spatial planning constraints, and social factors (Radwanek-Bak 2007; Uberman 2011). Environmental and spatial planning, including social factors are of major importance because of today's awareness of environmental issues. The objective information on the accessibility of a given deposit for development is important for public authorities responsible for spatial policy, environmental protection, investors and local communities.

The aim of this study has been to propose and apply, on a case study, a geographically referenced, objective method to evaluate the accessibility of a large brown coal deposit 
area for possible open-cast mine development. The accessibility was articulated as conflicting with the present day land use functions and designations representing environmental and spatial factors of the terrain above the documented mineral deposit. For the purpose of this analysis, a multicriteria spatial data analysis methodology based on the combination of Analytical Hierarchy Process (AHP) and the Weighted Linear Combination (WLC) method in geographic information system (GIS) was proposed and its applicability studied on a case of brown coal deposit located in SW Poland.

These methods belong to the multicriteria analysis (MCA) also referred as multicriteria evaluation (MCE) methods and allow for the analysis of complex, multidimensional trade-offs between choice alternatives, for example, locations or suitability analysis of an area (Meng et al. 2011). Spatial multicriteria analysis can be described as a process that combines and transforms geographically referenced data into a resultant decision. The GIS data are usually organized as vector or raster format thematic datasets called maps or layers. In recent years, various MCE methods have been developed and implemented in GIS, providing the capability of taking into consideration multiple dimensions in decision-making processes as proposed by (Jankowski 1995). Malczewski (2004, 2006) provides a concise review of these methods, which include deterministic, probabilistic and fuzzy-based multi-attribute and multi-objective methods. Among the various multiattribute methods, such as Boolean operator overlay, Weighted Linear Combination (WLC), Ordered Weighted Averaging (OWA), Analytical Hierarchy Process (AHP), etc., the first two are the most straightforward and widely employed for site-selection studies and suitability analysis (Malczewski 2004; Drobne and Lisec 2009). The WLC method is a variant of the OWA method, which involves two sets of weights: criterion weights and order weights. The first one is assigned to a given criterion or attribute for all locations in a study area to indicate its relative importance. The order weights are associated with the criterion values on a location-by-location basis (Boroushaki and Malczewski 2008). The Boolean operator overlay is a simpler procedure, in which criterion maps are combined by means of simple aggregation using, for example, intersection or union operators. The method does not allow for the use of weights. In the WLC method, continuous criteria are standardized to a common numeric range, and then combined by means of weighted average to produce an output map (Carver 1991; Drobne and Lisec 2009). In cases when constraints apply (e.g. restricted areas), Boolean constraints can be introduced in the WLC procedure.

The AHP methodology proposed by Saaty (1980) enables decomposition of a complex decision problem into sub-problems and construction of a ranking for a finite set of variants using an Eigen vector approach to pair-wise comparison of criteria. Because of its flexibility, AHP can be combined with other methods, e.g. WLC and can be used to determine weights of factors in MCE.

The AHP and WLC methods have been selected for the purpose of the presented study because of their relative straightforwardness and flexibility to combine with other techniques. Both methods are further explained in the chapter "Method" and a selection of their applications is described below.

The AHP method has been applied-either standalone or in combination with other techniques-in a wide range of different fields such as selection, evaluation, benefitcost analysis, allocations, planning and development, priority and ranking, and decision-making. A review of these applications has been done, for example, by Vaidya and Kumar (2006). With respect to mineral deposit ranking, selecting or mining, AHP has been used for example by Uberman and Ostrega (2008), Ptak (2012), and Sobczyk and Badera (2013). The first case concerns a ranking of selected undeveloped brown coal deposits in Poland. In this study, a multicriteria and multilevel model based on AHP has been proposed with the aim to determine a ranking of the analysed brown coal deposits. The main criteria of the model comprised factors such as geological, mining, economical, spatial, environmental and social conditions, and the variants were the particular mineral deposits. Ptak (2012) has employed AHP to construct an evaluation method for assessment of rock mineral deposits development of which could affect Nature $2000^{1}$ areas. The study by Sobczyk and Badera (2013) examined the possibilities of predicting which of the specified hard coal deposits are relatively less contentious with regard to local economic, social and environmental determinants. Other noteworthy applications include, the study by Gupta and Kumar (2012) which examines the application of the AHP for the selection of an appropriate stoping method for mining underground ore deposit from a group of alternatives, and the study by Dey and Ramcharan (2008) who have proposed an AHP-based analytical framework for site selection for the expansion of a limestone quarry operations to support cement production.

Examples of AHP application combined with other techniques (e.g. GIS) include landslide susceptibilitymapping (Rozos et al. 2011) and landfill site-selection methodologies based on the fuzzy set theory used to standardize criteria with fuzzy membership functions and the AHP method to establish the relative importance of the

\footnotetext{
${ }^{1}$ Nature 2000 is a network of nature protection areas in the territory of the European Union. It comprises various types of protected areas, mainly of Special Areas of Conservation (SACs) and Special Protection Areas (SPAs) (Eionet 2014).
} 
criteria (Donevska et al. 2012; Aydi et al. 2013). Bathrellos et al. (2012) applied an AHP- and GIS-based method for an integrated evaluation of areas suitable for urban growth with respect to natural hazards and geological and geomorphological parameters. Panagopoulos et al. (2012) proposed a multicriteria spatial data analysis method to determine potential water demand on the Lesvos island (Greece).

With respect to mineral resources, Hyder (2012) has applied GIS map overlay and AHP methods to propose a model for selecting suitable sites for underground coal gasification in any given area of interest, and Karakas (2013) has applied the WLC method to assess new sources of aggregates based on geological and land-use maps. Map overlay has also been used by Blachowski (2014) in GIS based valorization method for rock mineral deposits.

The aim of the research presented in this paper has been to develop a combined AHP and WLC method for assessing spatial accessibility of a brown coal deposit for open-cast mining taking into consideration, the environmental and spatial planning factors and to apply it to a brown coal deposit in SW Poland. To the best of author's knowledge, there are no previous applications of the combination of AHP and WLC in GIS for solving this kind of problems.

Within the scope of this study, the AHP methodology has been used to determine weights of environmental and spatial criteria conditioning development of a brown coal deposit identified in an expert survey. GIS has been employed to produce and manage single-factor maps representing spatially the selected criteria, and the WLC method has been used to combine the criteria maps by means of a weighted average to produce map representing accessibility of the deposit area. Combination of these two methods in GIS has allowed for the spatial referencing of the analysed problem.

\section{Study area}

The study area concerns a large brown coal deposit located in SW Poland in the Dolnoslaskie Province. It consists of three coal fields: Legnica W, Legnica $\mathrm{N}$ and Legnica S, which are accompanied by two smaller, secondary, deposits named Scinawa and Ruja. Locations of the Legnica and the other brown coal deposits are shown in Fig. 1. The Legnica field is considered to be, in terms of the quantity and quality of the mineral, as well as geological and mining conditions, one of the most significant potential deposits in the country. The mentioned two smaller deposits are not regarded as potential sources of coal. The anticipated economic geological resources in place for the Legnica deposit are 3,425,999 thousand tonnes (PGI 2013a). The resources for particular coal fields are given in Table 1.

The local geology precludes underground gasification of the coal deposit at the present state of technological knowledge, making open-cast mining the most probable mining method if the deposit were to be developed (Bednarczyk 2008; Uberman 2011).

The spatial extent of the study extends from $X=291,300$ to $X=324,450 \mathrm{~m}$ and from $Y=362,700$ to $Y=405,850 \mathrm{~m}$ expressed in the Polish Coordinate System UWPP 1992 (Fig. 1).

Poland produces approximately one third of its energy from brown coal and is the second largest European consumer of coal ( brown and hard coal put together). The national strategy regarding energy production expressed in the National Energy Policy until 2030 (Ministry of Economy 2009) states that production of energy from this nonrenewable fossil resource will be continued alongside other renewable and non-renewable sources. This implies that in the horizon of two or three decades, new brown coal deposits will have to be developed to provide the necessary resources. Poland has large deposits of brown coal located mainly in its central, western and south-western parts. These deposits have been subjected to numerous rankings made with different methodologies usually taking into account technological and economical aspects of opening new open-cast mines. These rankings have been summarized by Uberman (2011). In all of these rankings, the Legnica deposit is highly positioned. The National Energy Policy also identifies this deposit as one of the few potential ones for future development.

The decision to start a new open-cast mining project requires careful consideration of numerous factors including geological, mining, environmental, spatial and social criteria of evaluation (Uberman 2011; Uberman and $\mathrm{Na}$ woryta 2012). The information on pro et contra for the development of a particular deposit is important for public authorities responsible for spatial policy. The geological and mining conditions are usually well documented as is done in this case. The environmental and spatial factors are of growing concern for the society; therefore, this study has been undertaken to propose a methodology for objective assessment of these two groups of criteria for a possible open-cast mining project.

\section{Methodology}

The analysis of accessibility for the area of a documented brown coal deposit follows a case study approach and has been undertaken with the combination of the AHP and the WLP methods in GIS. 

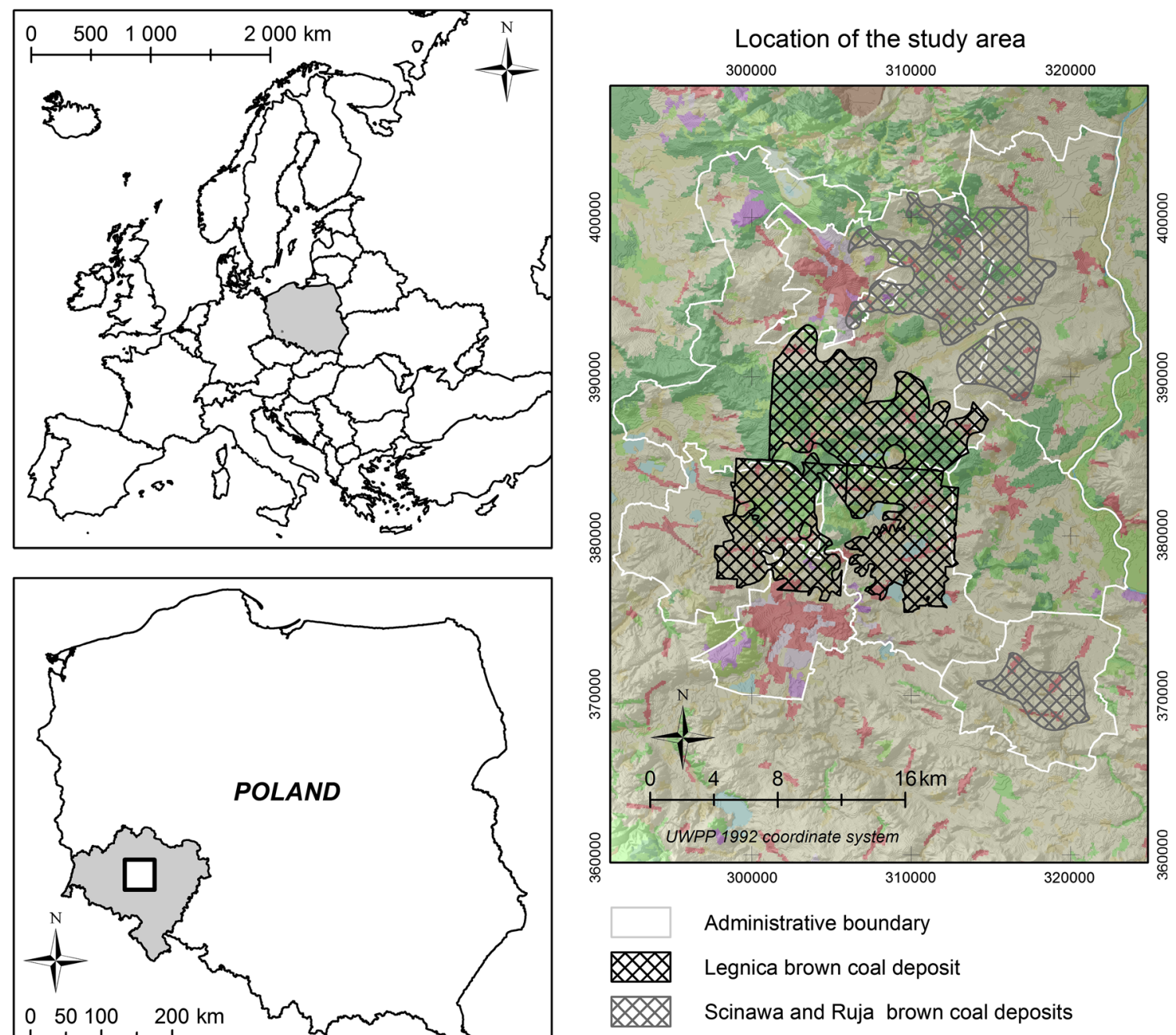

Fig. 1 Location of the study area-the Legnica brown coal deposits in SW Poland

Table 1 The anticipated economic geological resources in place for the Legnica deposit (PGI 2013a)

\begin{tabular}{lr}
\hline Name of deposit field & Geological resources ('000' tonnes) \\
\hline Legnica W & 863,638 \\
Legnica N & $1,723,049$ \\
Legnica E & 839,312 \\
\hline
\end{tabular}

\section{Analytical hierarchy process}

In the AHP method, the problem is analysed in a hierarchical structure, usually composed of several levels, i.e. objective, criteria, sub-criteria and variants. The sub-criteria levels are optional. The basic steps in this methods include (Vaidya and Kumar 2006) the following:

1. State the problem/objective;

2. Identify the criteria that influence the decision;

3. Structure the problem in a hierarchy of different levels constituting objective, criteria, sub-criteria and variants;
4. Compare each element in the corresponding level and calibrate them on the numerical scale. This requires $n(n-1) / 2$ comparisons, where $n$ is the number of elements with the considerations that diagonal elements are equal and the other elements will simply be the reciprocals of the earlier comparisons;

5. Perform calculations to find the maximum Eigen value, Consistency Index (CI), Consistency Ratio (CR), and normalized values for each criterion/variant; and

6. If the maximum Eigen value, CI, and CR are satisfactory, then decision is taken based on the normalized values; else, the procedure is repeated till these values lie in a desired range.

In step 3, the top level reflects the overall objective of the problem. The factors influencing the decision are represented in intermediate levels. The lowest level represents the variants. Once a hierarchy is constructed, the relative importances of the criteria in each level of the hierarchy are determined from their pairwise comparisons. The 
Table 2 The 9-point scale for pairwise comparison of criteria (Saaty 1987)

\begin{tabular}{ll}
\hline $\begin{array}{l}\text { Intensity of pairwise } \\
\text { comparison }\end{array}$ & Importance \\
\hline 1 & $\begin{array}{l}\text { Equal importance, two activities contribute } \\
\text { equally to the object } \\
\text { Moderate importance, slightly favours one } \\
\text { over another } \\
\text { Essential or strong importance, strongly } \\
\text { favours one over another } \\
\text { Demonstrated importance, dominance of the } \\
\text { demonstrated importance in practice } \\
\text { Extreme importance, evidence favouring one } \\
\text { over another of highest possible order of } \\
\text { affirmation }\end{array}$ \\
9 & $\begin{array}{c}\text { Intermediate values, when compromise is } \\
\text { needed }\end{array}$ \\
\hline
\end{tabular}

comparisons (step 4) can be derived from real measurements or a grading scale reflecting decision-maker's preferences (Saaty 1980). The preferences determined with relative grades expressed as numerical values, usually 1-9, where 1 indicates that the compared criteria are equivalent and 9 indicates that the first of the compared elements is strongly preferred with respect to the other element (Table 2). On this basis, preference matrixes are constructed taking into account the following principles: a given element of the matrix is equivalent to itself, i.e. equal to 1 , and the value of element $a$ with respect to element $b$ is the reciprocal of the value of element $b$ with respect to element $a$ (1) (Saaty 2008).

$M=\left[\begin{array}{ccc}a_{11}=1 & a_{12} & a_{1 n} \\ a_{21} & 1 & a_{2 n} \\ a_{n 1} & a_{n 2} & a_{n n}=1\end{array}\right]$

The values of the normalized matrix are determined based on Eq. (2) and priority vectors indicating weights of elements from Eq. (3):

$w_{i j}=\frac{a_{i j}}{\sum_{i=1}^{n} a_{i j}}$

$w_{i}=\sum_{j=1}^{n} w_{j} a_{i j}$

where

$w_{j}=\frac{\sum_{i=1}^{n} w_{i j}}{n}$

A test for the degree of consistency of the derived weights is performed to check the consistency of experts' judgements. It involves calculation of the Consistency Ratio (CR), which indicates the probability that the matrix values have been randomly generated. According to Saaty (1980) matrix that has a Consistency Ratio greater than
0.10 should be re-evaluated. The Consistency Ratio is calculated from the formula (5):

$C R=\frac{C I}{R I}$

where $C I$ is the Consistency Index, and $R I$ is the random index.

The $\mathrm{CI}$ is calculated as follows:

$C I=\frac{-n}{n-1}$

where $\lambda$ is the average value of the consistency vector, and $n$ is the number of criteria.

The Random Index (RI) is the Consistency Index of a randomly generated pairwise comparison matrix. The RI values depend on the number of compared elements and can be found in the literature, e.g. (Saaty 1987; Bagla and Gupta 2013).

\section{Weighted Linear Combination}

A WLC is an analytical method that can be used when multiple attributes must be taken into consideration, for example, in suitability modelling or site selection. Every attribute that is considered is called a criterion. Each criterion is assigned a weight based on its importance. The criteria are represented spatially by single-factor maps or layers, and the result is a multi-attribute map with final score. The higher the score the more suitable the area (Hejmanowska and Hnat 2009; Meng et al. 2011). The general framework of WLC procedure is as follows. First, numeric ranges are assigned to a set of continuous criteria. Next, the numeric ranges are combined into a weighted average. The weights are assigned directly to each attribute map. The total score is calculated by multiplying the weight assigned to each attribute by the scaled value given for that attribute and summing the products over all attributes This method can be used in any GIS with map overlay capabilities, and allows for combining the evaluation criterion map layers in order to determine the composite map layer, which is the output (Drobne \& Lisec 2009). The final score is obtained from following the formula (7):

$S=\sum_{i=1}^{n} w_{i} k_{i}$

where $S$ cell score of the final map, $w_{i}$ weight of a criterium $i=1, \ldots, n, k$ value of criterium $i=1, \ldots n, n$ number of criteria.

\section{Application}

The proposed algorithm for brown coal deposit area accessibility assessment with the combined AHP/WLC 
Table 3 Comparison matrix obtained from expert rating

\begin{tabular}{|c|c|c|c|c|c|c|c|c|c|c|c|c|c|c|c|}
\hline & 1 & 2 & 3 & 4 & 5 & 6 & 7 & 8 & 9 & 10 & 11 & 12 & 13 & 14 & 15 \\
\hline 1 & 1.00 & 2.89 & 5.69 & 4.26 & 2.81 & 4.50 & 0.63 & 0.61 & 2.65 & 4.63 & 1.41 & 0.33 & 2.50 & 2.05 & 0.75 \\
\hline 2 & 0.35 & 1.00 & 3.18 & 1.15 & 1.44 & 1.92 & 0.36 & 0.31 & 0.67 & 3.81 & 0.62 & 0.18 & 0.33 & 0.50 & 0.21 \\
\hline 3 & 0.18 & 0.31 & 1.00 & 0.27 & 0.50 & 0.92 & 0.26 & 0.24 & 0.33 & 1.36 & 0.30 & 0.15 & 0.27 & 0.30 & 0.18 \\
\hline 4 & 0.23 & 0.87 & 3.67 & 1.00 & 0.75 & 1.96 & 0.26 & 0.28 & 0.60 & 3.75 & 0.62 & 0.18 & 0.43 & 0.52 & 0.21 \\
\hline 5 & 0.36 & 0.69 & 2.00 & 1.34 & 1.00 & 0.60 & 0.19 & 0.28 & 0.33 & 1.80 & 0.38 & 0.16 & 0.33 & 0.34 & 0.20 \\
\hline 6 & 0.22 & 0.52 & 1.09 & 0.51 & 1.67 & 1.00 & 0.24 & 0.28 & 0.43 & 1.88 & 0.38 & 0.16 & 0.33 & 0.34 & 0.20 \\
\hline 7 & 1.58 & 2.78 & 3.89 & 3.78 & 5.25 & 4.25 & 1.00 & 0.50 & 1.50 & 4.97 & 1.45 & 0.60 & 0.83 & 1.44 & 0.51 \\
\hline 8 & 1.63 & 3.19 & 4.19 & 3.53 & 3.56 & 3.56 & 2.00 & 1.00 & 3.16 & 5.05 & 1.96 & 0.50 & 0.70 & 0.75 & 0.59 \\
\hline 9 & 0.38 & 1.50 & 3.00 & 1.67 & 3.00 & 2.33 & 0.67 & 0.32 & 1.00 & 5.30 & 1.11 & 0.18 & 0.49 & 0.73 & 0.29 \\
\hline 10 & 0.22 & 0.26 & 0.73 & 0.27 & 0.56 & 0.53 & 0.20 & 0.20 & 0.19 & 1.00 & 0.36 & 0.13 & 0.26 & 0.25 & 0.16 \\
\hline 11 & 0.71 & 1.62 & 3.33 & 1.62 & 2.67 & 2.67 & 0.69 & 0.51 & 0.90 & 2.76 & 1.00 & 0.21 & 0.33 & 0.39 & 0.27 \\
\hline 12 & 3.00 & 5.67 & 6.67 & 5.67 & 6.33 & 6.33 & 1.67 & 2.00 & 5.50 & 7.67 & 4.67 & 1.00 & 4.26 & 6.18 & 1.09 \\
\hline 13 & 0.40 & 3.00 & 3.67 & 2.33 & 3.00 & 3.00 & 1.20 & 1.42 & 2.03 & 3.87 & 3.02 & 0.23 & 1.00 & 0.88 & 0.38 \\
\hline 14 & 0.49 & 2.00 & 3.33 & 1.92 & 2.92 & 2.92 & 0.69 & 1.33 & 1.36 & 4.00 & 2.56 & 0.16 & 1.14 & 1.00 & 0.40 \\
\hline 15 & 1.33 & 4.83 & 5.67 & 4.67 & 5.00 & 5.00 & 1.94 & 1.69 & 3.50 & 6.33 & 3.67 & 0.92 & 2.67 & 2.50 & 1.00 \\
\hline Sum & 12.07 & 31.14 & 51.11 & 33.99 & 40.44 & 41.49 & 12.00 & 10.99 & 24.15 & 58.18 & 23.48 & 5.09 & 15.88 & 18.17 & 6.43 \\
\hline
\end{tabular}

method adopted in this research consists of the following steps:

Step 1 identifying the spatial and environmental factors representing accessibility criteria by group of experts;

Step 2 developing the AHP framework model and deriving the weights of factors through pairwise comparison based on the experts assessments;

Step 3 verifying consistency of the pairwise comparison with Consistency Ratio (CR);

Step 4 developing GIS database of each identified criterion;

Step 5 applying weights to single criterion maps and performing weighted linear combination; and

Step 6 classifying and interpreting the results of the accessibility modelling.

\section{Step I: Identification of accessibility criteria}

In the first step, the land use functions conflicting with the development of brown coal deposits have been identified. The environmental and spatial conflicts have been determined based on a survey of a group of experts representing spatial planning, nature protection, mining, agriculture, forestry, technical infrastructure, transport, public administration and higher education fields. The identified conflicts are

1. build-up areas;

2. main roads (national and regional);

3. roads other (local);
4. railways;

5. electrical power network;

6. gas network;

7. surface waters (flowing, still);

8. protected underground waters;

9. good-quality arable land (quality classes 1-5);

10. arable land (other);

11. forest;

12. nature protection areas (nature reserves, landscape parks, landscape protection areas, Nature2000 areas);

13. areas of valuable nature (sites of ecological use);

14. ecological corridors; and

15. national heritage sites and monuments.

\section{Step II: Weighting of the accessibility criteria}

In the next step, the same group of experts has been asked to do a comparative assessment of all criteria pairs. Average value of their pairwise criteria assessment according to the scale proposed by Saaty (Table 2) has been used to form the comparison matrix (Table 3). The table has been then used to determine the weight of each criterion and values of the consistency vector $(\lambda)$ according to the AHP methodology (Table 4).

\section{Step III: Consistency of pairwise comparison}

This step is concerned with the analysis of the degree of consistency of the derived weights following the procedure described by Saaty (1980) and presented earlier in this 
Table 4 Normalized pairwise comparison matrix

\begin{tabular}{lllllllllllllllllll}
\hline & 1 & 2 & 3 & 4 & 5 & 6 & 7 & 8 & 9 & 10 & 11 & 12 & 13 & 14 & 15 & Weight & $\lambda$ \\
\hline 1. & 0.08 & 0.09 & 0.11 & 0.13 & 0.07 & 0.11 & 0.05 & 0.06 & 0.11 & 0.08 & 0.06 & 0.07 & 0.16 & 0.11 & 0.12 & 0093 & 16.009 \\
2. & 0.03 & 0.03 & 0.06 & 0.03 & 0.04 & 0.05 & 0.03 & 0.03 & 0.03 & 0.07 & 0.03 & 0.03 & 0.02 & 0.03 & 0.03 & 0035 & 15.453 \\
3. & 0.01 & 0.01 & 0.02 & 0.01 & 0.01 & 0.02 & 0.02 & 0.02 & 0.01 & 0.02 & 0.01 & 0.03 & 0.02 & 0.02 & 0.03 & 0018 & 15.525 \\
4. & 0.02 & 0.03 & 0.07 & 0.03 & 0.02 & 0.05 & 0.02 & 0.03 & 0.02 & 0.06 & 0.03 & 0.03 & 0.03 & 0.03 & 0.03 & 0033 & 15.403 \\
5. & 0.03 & 0.02 & 0.04 & 0.04 & 0.02 & 0.01 & 0.02 & 0.03 & 0.01 & 0.03 & 0.02 & 0.03 & 0.02 & 0.02 & 0.03 & 0025 & 15.648 \\
6. & 0.02 & 0.02 & 0.02 & 0.02 & 0.04 & 0.02 & 0.02 & 0.03 & 0.02 & 0.03 & 0.02 & 0.03 & 0.02 & 0.02 & 0.03 & 0023 & 15.549 \\
7. & 0.13 & 0.09 & 0.08 & 0.11 & 0.13 & 0.10 & 0.08 & 0.05 & 0.06 & 0.09 & 0.06 & 0.12 & 0.05 & 0.08 & 0.08 & 0087 & 15.764 \\
8. & 0.13 & 0.10 & 0.08 & 0.10 & 0.09 & 0.09 & 0.17 & 0.09 & 0.13 & 0.09 & 0.08 & 0.10 & 0.04 & 0.04 & 0.09 & 0095 & 15.812 \\
9. & 0.03 & 0.05 & 0.06 & 0.05 & 0.07 & 0.06 & 0.06 & 0.03 & 0.04 & 0.09 & 0.05 & 0.04 & 0.03 & 0.04 & 0.04 & 0049 & 15.562 \\
10. & 0.02 & 0.01 & 0.01 & 0.01 & 0.01 & 0.01 & 0.02 & 0.02 & 0.01 & 0.02 & 0.02 & 0.03 & 0.02 & 0.01 & 0.02 & 0015 & 15.616 \\
11. & 0.06 & 0.05 & 0.07 & 0.05 & 0.07 & 0.06 & 0.06 & 0.05 & 0.04 & 0.05 & 0.04 & 0.04 & 0.02 & 0.02 & 0.04 & 0047 & 15.602 \\
12. & 0.25 & 0.18 & 0.13 & 0.17 & 0.16 & 0.15 & 0.14 & 0.18 & 0.23 & 0.13 & 0.20 & 0.20 & 0.27 & 0.34 & 0.17 & 0193 & 16.216 \\
13. & 0.03 & 0.10 & 0.07 & 0.07 & 0.07 & 0.07 & 0.10 & 0.13 & 0.08 & 0.07 & 0.13 & 0.05 & 0.06 & 0.05 & 0.06 & 0076 & 15.886 \\
14. & 0.04 & 0.06 & 0.07 & 0.06 & 0.07 & 0.07 & 0.06 & 0.12 & 0.06 & 0.07 & 0.11 & 0.03 & 0.07 & 0.06 & 0.06 & 0067 & 15.855 \\
15. & 0.11 & 0.16 & 0.11 & 0.14 & 0.12 & 0.12 & 0.16 & 0.15 & 0.14 & 0.11 & 0.16 & 0.18 & 0.17 & 0.14 & 0.16 & 0142 & 15.931 \\
Sum & 1.00 & 1.00 & 1.00 & 1.00 & 1.00 & 1.00 & 1.00 & 1.00 & 1.00 & 1.00 & 1.00 & 1.00 & 1.00 & 1.00 & 1.00 & 1000 & - \\
\hline
\end{tabular}

Table 5 Results of assessment of the degree of consistency of the comparison matrix

\begin{tabular}{lllll}
\hline$n$ & RI & $\lambda$ & CI & CR \\
\hline 15 & 1.59 & 15.722 & 0052 & 0032 \\
\hline
\end{tabular}

paper. The RI value for 15 elements is 1.59 (Saaty 1987). The results of calculations using the Eqs. (5) and (6) are presented in Table 5.

The calculated value of the Consistency Ratio is 0.032 , which is below the 0.1 threshold value suggested for reevaluation of the criteria values.

The most significant functional conflicts between spatial and environmental criteria and the potential open-cast mining, based on the results of the above analysis, are nature protection areas (weight 0.19), cultural and historical monuments (0.14), inhabited areas (weight 0.09), underground water reservoirs (weight 0.09 ) and surface waters (weight 0.09). Thus, environmental, cultural and human settlement factors have been found to be the most prohibiting.

The criteria weights have been used for Weighted Linear Combination-GIS analysis. Locations of major land use functions and designations in the boundaries of the Legnica brown coal deposits are show in Fig. 2.

\section{Step IV: Spatial representation of criteria in GIS}

The spatial, source, data used in the case study are composed of vector maps representing the identified criteria: build-up areas, main roads (national and regional), roads other (local), railways, electrical power network, gas network, surface waters (flowing, still), protected underground waters, good-quality arable land (quality classes 1-5), arable land (other), forest, nature protection areas (nature reserves, landscape parks, landscape protection areas, Nature 2000 areas), areas of valuable nature (sites of ecological use), ecological corridors, national heritage sites and monuments. These data have been acquired from the Provincial Centre for Geodesic and Cartographic Documentation. The boundaries of the Legnica brown coal deposit were obtained as vector shape files from the Polish Central Geological Database run by the Polish Geological Institute (http://web3.pgi.gov.pl/dwm/DownloadManager v1.aspx?lang=en) (PGI 2013b). Vector maps have been converted to raster format for the purpose of the WLC analysis. The pixel size of each raster map was set at $50 \mathrm{~m}$. Each raster is composed of 663 columns and 863 records.

\section{Step V: Weighted Linear Combination}

To apply the WLC analysis, the ArcGIS 10.2 software package and its Spatial Analyst extension have been used (ESRI 2013). The Weighted Sum function, which overlays input raster maps multiplying each by their given weight and summing them together was used.

Each criterion, identified in step I, has been expressed as a raster map and standardized to a $0-1$ scale where 0 means that the given feature (criterion) does not exit and 1 means that it exists in space. For example, on the raster map representing forests pixel value equal to 1 represents forests and 0 the remaining areas. 


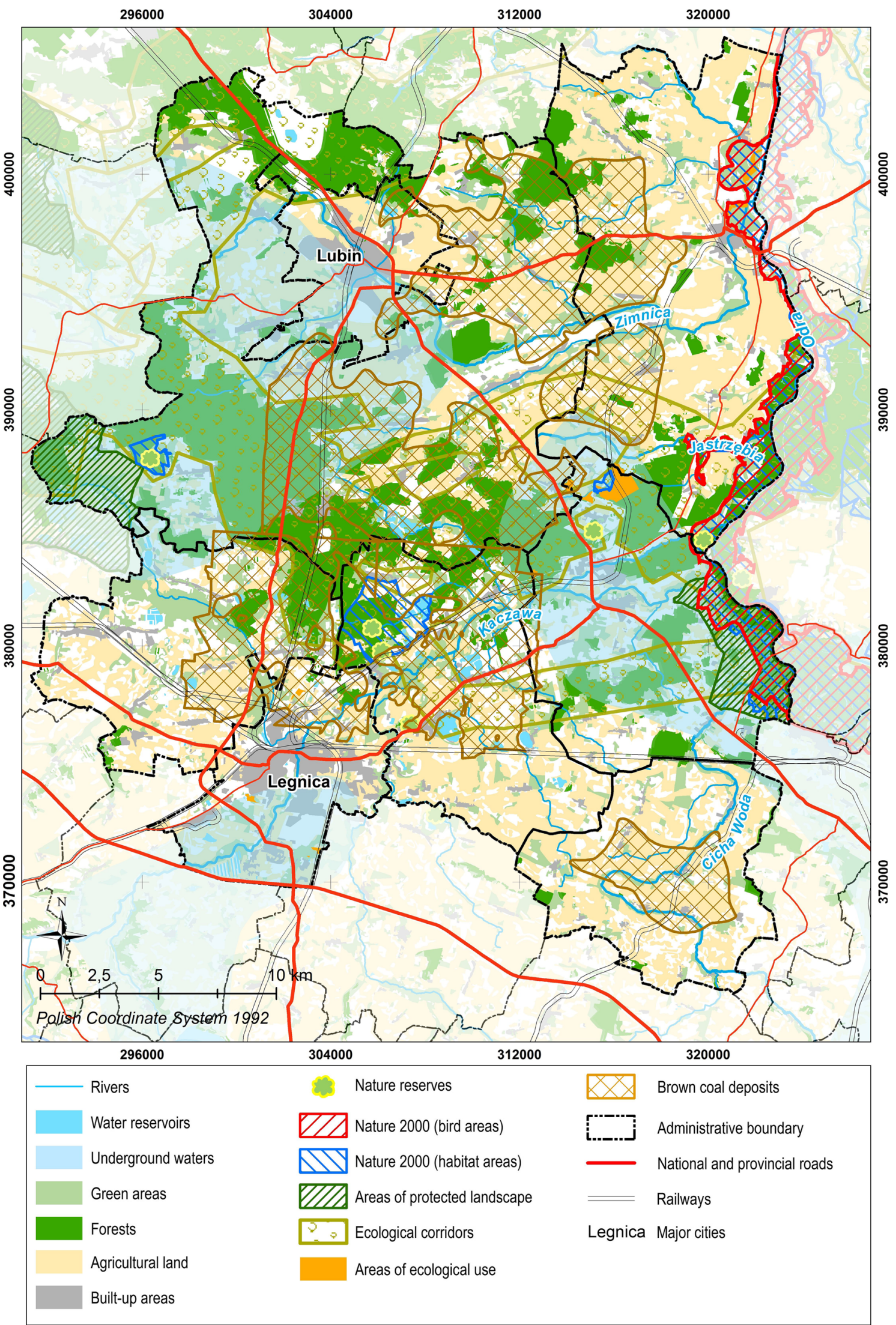

Fig. 2 Main land use functions and designations in the Legnica brown coal deposit area 
Fig. 3 Scheme of the Weighted Linear Combination procedure in GIS
Table 6 Statistical results of the WLC accessibility analysis in GIS

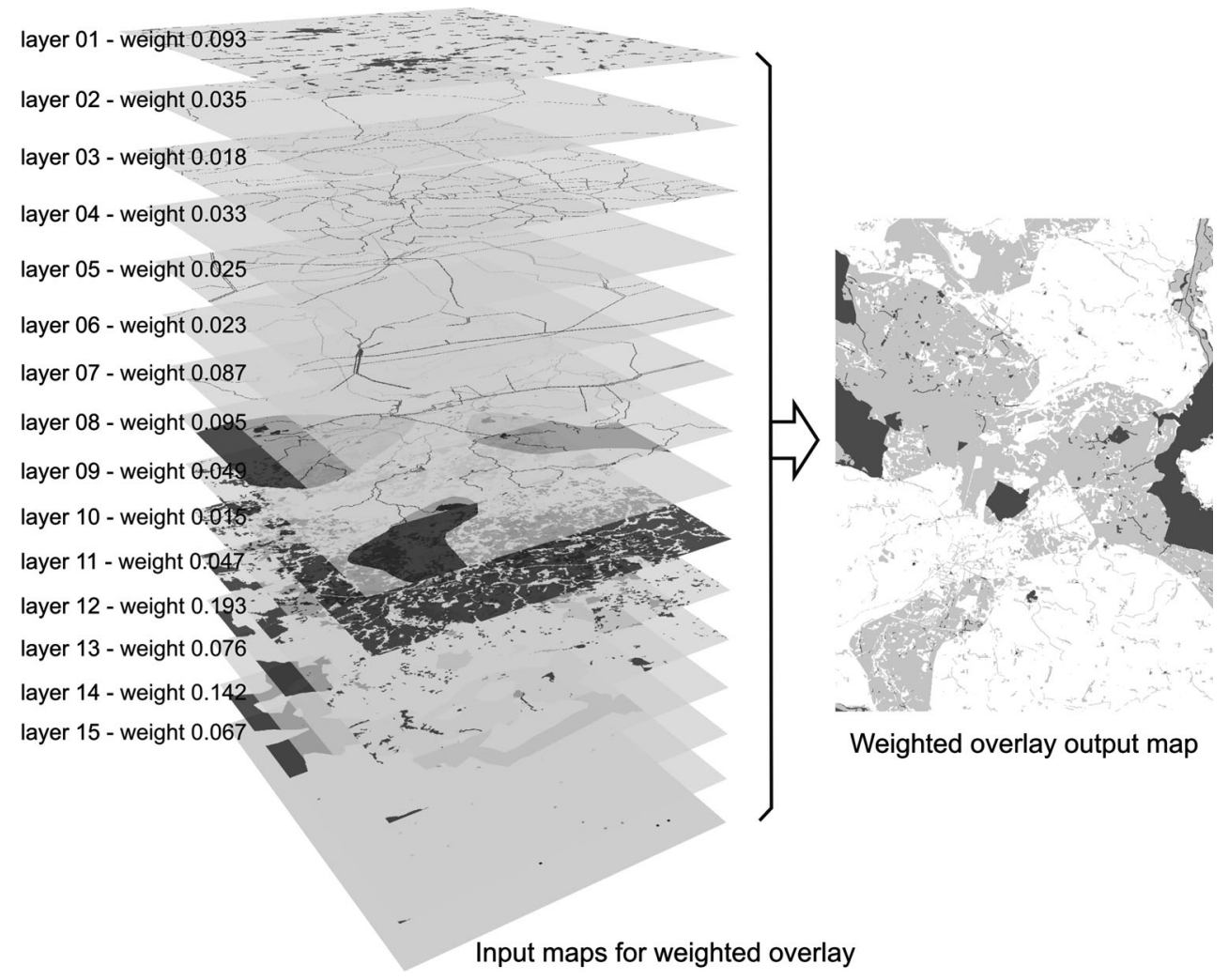

\begin{tabular}{llll}
\hline & Max. cell value & Mean cell value & Standard deviation \\
\hline Total analysed area & 0.55 & 0.11 & 0.09 \\
Area of the Legnica deposit & 0.55 & 0.10 & 0.07 \\
\hline
\end{tabular}

The standardized raster maps were multiplied by the corresponding weights obtained in Step II to construct the weighted standardized map layers. The weighted sum operation was performed on the standardized raster maps following the formula (7) to generate the overall accessibility composite raster map as shown schematically in Fig. 3.

\section{Step VI: Classification of output accessibility map}

The output raster map has been categorized into classes representing the deposit accessibility based on the raster values histogram. It has been discussed in the following section.

\section{Results and discussion}

The maximum pixel value in the output raster map obtained with the WLC analysis is 0.55 , and the mean pixel value for the deposit area is 0.10 . The results for the entire study area and for the deposit area are shown in Table 6.
Based on the statistics presented in Table 6 and the histogram of raster values, two classifications of brown coal deposit accessibility have been proposed. The first consists of two classes: below and above the mean pixel value. The area with total score below the mean value (value range 0.01-0.11) is regarded as the least inaccessible, and the area with total score above the mean value the most inaccessible (value range $0.12-0.55$ ). The results are shown in Fig. 4 and the statistics in Table 7 . The second classification is based on the natural breaks (Jenks) optimization method (Jenks 1967) and consists of three classes: the most inaccessible (value range $0.25-0.55$ ), relatively inaccessible (value range $0.12-0.24$ ) and the least inaccessible (value range $0.01-0.11$ ). The results are shown in Fig. 5 and the statistics in Table 8 .

The total area of the 3 fields of the Legnica brown coal deposit equals to $161.26 \mathrm{~km}^{2}$. The western (W) and the eastern (E) fields are comparatively the same size $\left(47.18 \mathrm{~km}^{2}\right.$ and $45.65 \mathrm{~km}^{2}$, respectively). The northern (N) field is the largest with the size of over $68 \mathrm{~km}^{2}$. Taking into account the mean value of the results of the GIS analysis as the threshold value, the Legnica $\mathrm{N}$ field is 
Fig. 4 Results of the MCE accessibility analysis classified into two classes
Table 7 Results of the Legnica deposit area accessibility classification (2 classes)

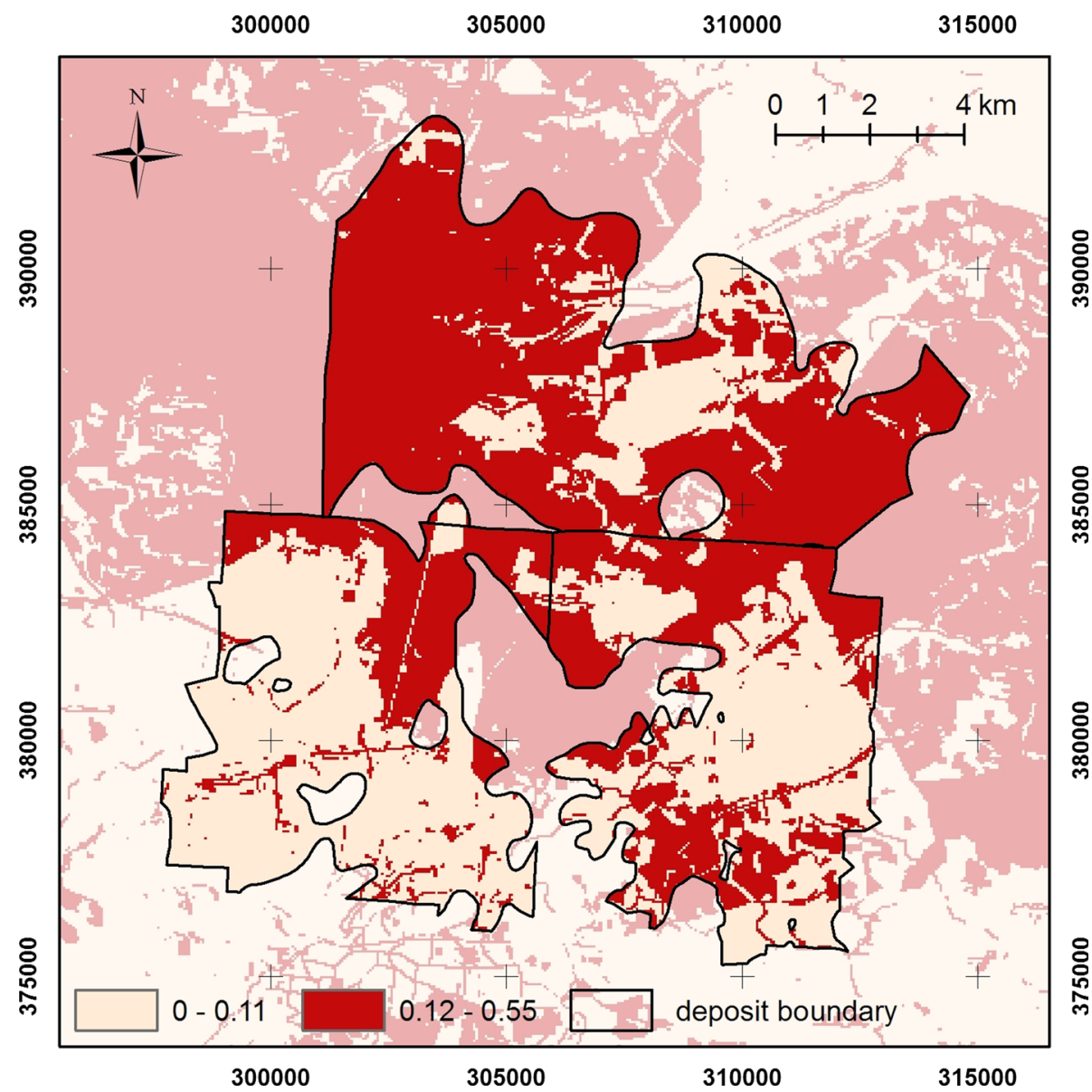

\begin{tabular}{|c|c|c|c|c|c|}
\hline \multirow[t]{2}{*}{ Name of deposit field } & \multirow[t]{2}{*}{ Total area $\left(\mathrm{km}^{2}\right)$} & \multicolumn{2}{|c|}{ Most inaccessible } & \multicolumn{2}{|c|}{ Least inaccessible } \\
\hline & & $\left(\mathrm{km}^{2}\right)$ & $(\%)$ & $\left(\mathrm{km}^{2}\right)$ & $(\%)$ \\
\hline Legnica W & 47.18 & 13.58 & 28.8 & 33.60 & 71.2 \\
\hline Legnica $\mathrm{N}$ & 68.43 & 54.25 & 79.3 & 14.18 & 20.7 \\
\hline Legnica E & 45.65 & 18.66 & 43.1 & 25.99 & 56.9 \\
\hline Altogether & 161.26 & 86.49 & 53.6 & 73.77 & 46.4 \\
\hline
\end{tabular}

relatively the most inaccessible with $79.3 \%$ of its area unsuitable for deposit development in terms of the considered, environmental and spatial, factors. The Legnica $\mathrm{W}$ field is the least inaccessible with $28.8 \%$ of its area above the mean value. This value for the third Legnica $E$ field is $43.1 \%$. In terms of the entire deposit area (three fields), the values are $54.25 \mathrm{~km}^{2}, 13.58 \mathrm{~km}^{2}$ and $18.56 \mathrm{~km}^{2}$, respectively. In general, 53.6 percent of the total deposit area is the most restricted for development and 46.4 percent relatively inaccessible.

Classification into three classes (Fig. 5) gives additional insight into the potential accessibility of the studied brown coal deposit area. The area ranked as the least inaccessible or conflicting is also the most compact in the Legnica $\mathrm{W}$ field and more fragmented in the Legnica $\mathrm{E}$ and Legnica $\mathrm{N}$ fields (Fig. 5)

The proposed method provided a quantitative evaluation of environmental and spatial factors determining the accessibility of a large brown coal deposit for its possible open-cast development. The WLC method produces a continuous map representing the suitability or in the presented case accessibility of an area for a particular purpose. Each of the standardized criteria of WLC expresses restrictions-the higher the score the more inaccessible the area for the planned land use. It is a good assessment, but it should be noted that a low value of one criterion can be compensated by a high value of another one, and this can be reflected in the final map. The continuous character of 
Fig. 5 Results of the MCE accessibility analysis classified into three classes

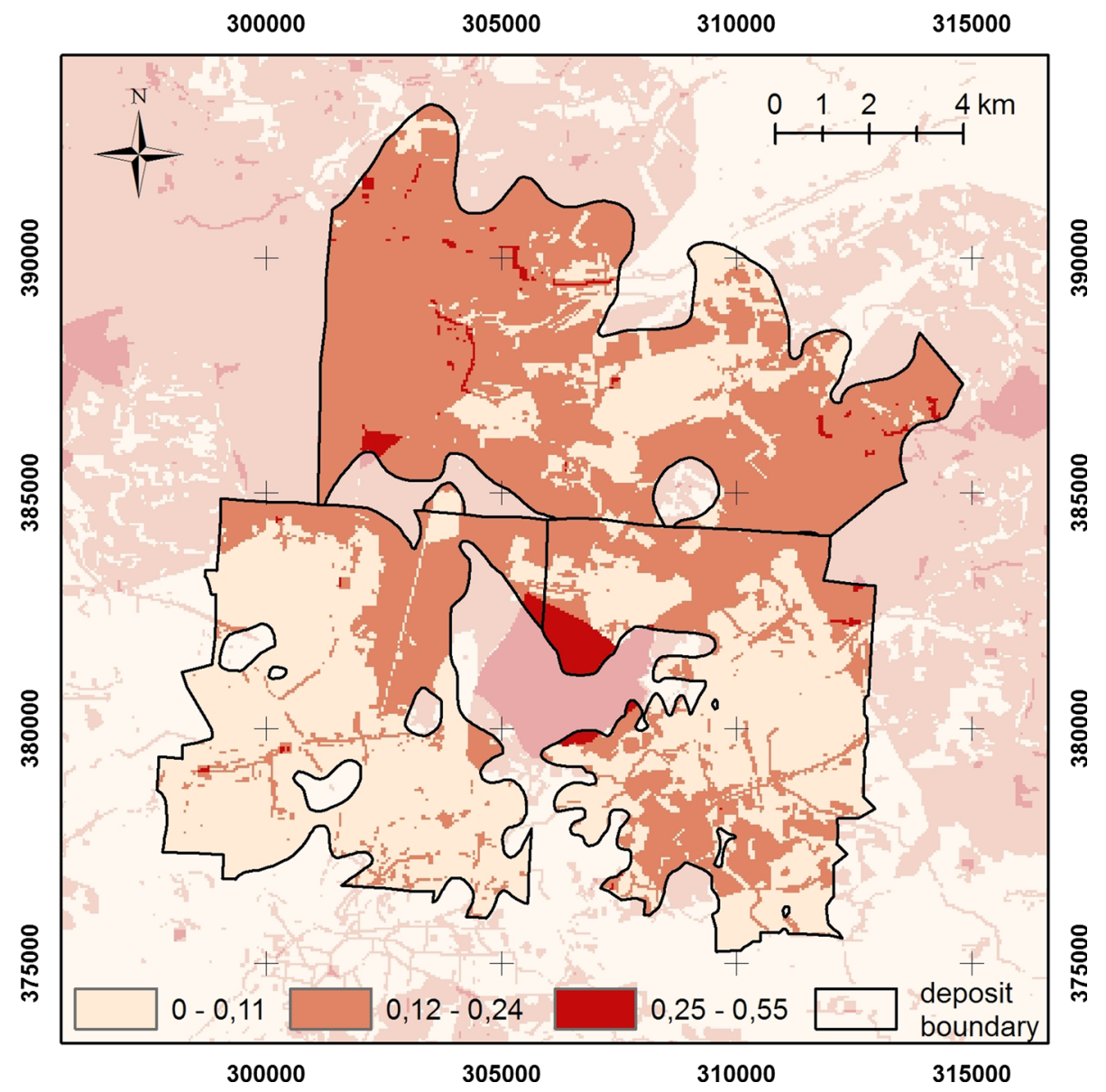

Table 8 Results of the Legnica deposit area accessibility classification

\begin{tabular}{|c|c|c|c|c|c|c|c|}
\hline \multirow[t]{2}{*}{ Name of deposit field } & \multirow[t]{2}{*}{ Total area $\left(\mathrm{km}^{2}\right)$} & \multicolumn{2}{|c|}{ Most inaccessible } & \multicolumn{2}{|c|}{ Relatively inaccessible } & \multicolumn{2}{|c|}{ Least inaccessible } \\
\hline & & $\overline{\left(\mathrm{km}^{2}\right)}$ & $(\%)$ & $\overline{\left(\mathrm{km}^{2}\right)}$ & $(\%)$ & $\overline{\left(\mathrm{km}^{2}\right)}$ & $(\%)$ \\
\hline Legnica $\mathrm{W}$ & 47.18 & 0.26 & 0.6 & 13.32 & 28.2 & 33.60 & 71.2 \\
\hline Legnica N & 68.43 & 1.37 & 2.0 & 52.88 & 77.3 & 14.18 & 20.7 \\
\hline Legnica E & 45.65 & 1.78 & 3.9 & 17.88 & 39.2 & 25.99 & 56.9 \\
\hline Alltogehter & 161.26 & 3.41 & 2.1 & 84.08 & 52.1 & 73.77 & 45.8 \\
\hline
\end{tabular}

the WLC criteria maps does not allow us to estimate exactly threshold values that would determine inaccessible and accessible areas. Therefore, the results should be read carefully. This is known as trade-off or substitutability (Drobne and Lisec 2009). If necessary, two additional methods can be applied to modify the procedure. The first is to introduce constraints and use Boolean operators such as AND or OR, which are absolute in nature to account for prohibited areas such as nature reserves. The second is to apply fuzzy membership measures in MCE, as suggested by (Jiang and Eastman 2000). In the case of this study, this was accounted for by adopting a strict threshold value (mean value of the final score) to distinguish between the most inaccessible and the least inaccessible areas.

The application of pairwise comparison method (AHP) in the assessment of criteria weights, which uses direct trade-off between each pair of compared factors, has the advantage of allowing for an organized, and in many cases hierarchical, structure of criteria, which provides the experts with a better focus on specific criteria during the weight-allocation process. The selection of attributescriteria for comparison has to take into account their completeness, which in this study was addressed by a survey of group of experts representing different disciplines. 


\section{Conclusions}

The results presented in this paper demonstrate the application of a combination of Analytical Hierarchy Process (AHP) and Weighted Linear Combination (WLC) in GIS for the purpose of determining the accessibility of an identified area-a documented brown coal deposit-for open-cast mining. The AHP method has been used to determine weights of environmental and spatial factors identified in an expert survey as criteria of accessibility. Altogether, 15 factors have been identified and the following have been found to be the most significant ones: location of important nature protection sites, cultural and historical sites, populated areas, underground water reservoirs and surface waters. The WLC has been used to produce the final composite map showing accessibility of the area based on the input criteria maps multiplied by weights obtained from the AHP. The adopted methodology has been tested in the case of a documented and undeveloped large brown coal deposit located in SW Poland. The obtained maximum score of the final map is 0.55 , while the mean value is 0.10 . Considering the latter as a threshold value between the least and the most inaccessible parts of the deposit area, it has been determined that 53.6 percent of the total deposit area is inaccessible, and 46.4 percent is relatively inaccessible. Analysing the three coal deposit fields in detail, the northern field is the most restricted (79.3 percent of its area) and the western one the least restricted (28.8\% of its area) for a possible mining project. The presented methodology is one of possible solutions for analysis of the deposit accessibility problem, the other ones being, for example, application of MCE or fuzzy set theory. However, it is one of the most straightforward, and keeping in mind its limitations such as possible compensation of one criterion by another one, a good first measure of the problem. The development of MCE methods in present-day GIS software presents advantages for decision makers such as politicians responsible for spatial development and mineral development and energy policies providing quantitative solutions of spatial decision problems.

The proposed approach has been intended firstly, to identify the most significant spatial and environmental constraints of mining a brown coal deposit according to an expert opinion and secondly, to determine the areas of their co-occurrence and thus assess the mineral deposit site's accessibility. The proposed methodology of evaluating accessibility of a mineral deposit site and the results of this study can be used to support sustainable spatial policy and spatial development at all levels of public administration.

Open Access This article is distributed under the terms of the Creative Commons Attribution 4.0 International License (http://creativecommons.org/licenses/by/4.0/), which permits unrestricted use, distribution, and reproduction in any medium, provided you give appropriate credit to the original author(s) and the source, provide a link to the Creative Commons license, and indicate if changes were made.

\section{References}

Aydi A, Zairi M, Dhia HB (2013) Minimization of environmental risk of landfill site using fuzzy logic, analytical hierarchy process, and weighted linear combination methodology in a geographic information system. Environ Earth Sci 68:1375-1389

Bagla V, Gupta A (2013) Site selection using optimization techniques. Intrnational J Sci Eng Res. 4(4). http://www.ijser.org/ paper/Site-Selection-Using-Optimization-Techniques.html. Accessed 8 Oct 2014

Bathrellos GD, Gaki-Papanastassiou K, Skilodimou HD, Papanastassiou D, Chousianitis KG (2012) Potential suitability for urban planning and industry development using natural hazard maps and geological-geomorphological parameters. Environ Earth Sci 66:537-548

Bednarczyk J (2008) Prospective scenarios of brown coal mining and processing into energy. Energy Policy J 11(1):73-88 (In Polish with English summary)

Blachowski J (2014) Spatial analysis of the mining and transport of rock minerals (aggregates) in the context of regional development. Environ Earth Sci 71:1327-1338

Boroushaki S, Malczewski J (2008) Implementing an extension of the analytical hierarchy process using ordered weighted averaging operators with fuzzy quantifiers in ArcGIS. Comput Geosci 34:399-410

Carver S (1991) Integrating multi-criteria evaluation with geographical information systems. Int $\mathrm{J}$ Geogr Inf Syst 5(3):321-339. doi:10.1080/02693799108927858

Dey PK, Ramcharan EK (2008) Analytic hierarchy process helps select site for limestone quarry expansion in Barbados. J Environ Manag 88:1384-1395

Donevska KR, Gorsevski PV, Jovanovski M, Peševski I (2012) Regional non-hazardous landfill site selection by integrating fuzzy logic, AHP and geographic information systems. Environ Earth Sci 67:121-131. doi:10.1007/s12665-011-1485-y

Drobne S, Lisec A (2009) Multi-attribute decision analysis in GIS: Weighted Linear Combination and Ordered Weighted Averaging. Informatica 33:459-474

Eionet-European Environment Information and Observation Network (2014). http://bd.eionet.europa.eu/activities/Natura_2000/index_ html. Accessed 3 Oct 2014

ESRI (2013) ArcGIS Help Library. http://resources.arcgis.com/en/ help/main/10.2. Accessed 20 Feb 2014

Gupta S, Kumar U (2012) An analytical hierarchy process (AHP)guided decision model for underground mining method selection. Int J Min Reclam Environ 26(4):324-336. doi:10.1080/ 17480930.2011 .622480

Hejmanowska B, Hnat E (2009) Multi-factoral evaluation of residential area locations: case study of podegrodzie local authority. Arch Photogramm Cartogr Remote Sens 20:109-121 (in Polish with English Summary)

Hyder Z (2012) Site Characterization, sustainability evaluation and life cycle emissions assessment of underground coal gasification. Doctoral dissertation. Faculty of Virginia Polytechnic Institute and State University. http://scholar.lib.vt.edu/theses/available/ etd-09132012-155859/unrestricted/Hyder_Z_D_2012.pdf. Accessed 18 Feb 2014 
Jankowski P (1995) Integrating geographical information systems and multiple criteria decision-making methods. Int J Geogr Inf Syst 9(3):251-273. doi:10.1080/02693799508902036

Jenks G (1967) The data model concept in statistical mapping. Int Yearb Cartogr 7:186-190

Jiang H, Eastman JR (2000) Application of fuzzy measures in multicriteria evaluation in GIS. Int J Geogr Inf Syst 14(2):173-184

Karakas A (2013) Defining the suitability of new crushed rock aggregate source areas in the North of Kocaeli Province using GIS. Bull Eng Geol Environ. doi:10.1007/s10064-013-0557-5

Malczewski J (2004) GIS-based land-use suitability analysis: a critical overview. Prog Plan 62:3-65

Malczewski J (2006) GIS-based multicriteria decision analysis: a survey of the literature. Int J Geogr Inf Sci 20(7):703-726. doi:10.1080/13658810600661508

Meng Y, Malczewski J, Boroushaki S (2011) GIS-based multicriteria decision analysis approach for mapping accessibility patterns of housing development sites: a case study in Canmore, Alberta. J Geogr Inf Syst 3:50-61. doi:10.436/jgis.2011.31004

Ministry of Economy (2009) Polish Energy Policy until 2030. Document accepted by the Council of Ministers on 10.11.2009. http://www.mg.gov.pl/files/upload/8134/Polityka\%20energetyczna \%20ost.pdf. Accessed 19 Feb 2014. (In Polish)

Panagopoulos GP, Bathrellos GD, Skilodimou HD, Martsouka FA (2012) Mapping urban water demands using multi-criteria analysis and GIS. Water Resour Manage 26:1347-1363

Polish Geological Institute (2013a) Mineral Resources of Poland, Brown Coal. http://geoportal.pgi.gov.pl/css/surowce/images/ 2012/pdf/brown_coal_2012.pdf. Accessed 31 Jan 2014

Polish Geological Institute (2013b) Central geological database. http://web3.pgi.gov.pl/dwm/DownloadManager_v1.aspx?lang=en. Accessed 02 Dec 2013

Ptak M (2012) The natural elements of the deposit classification method in nature 2000 sites-Kzn 2000/mAHP. J Wroclaw Univ Technol Inst Min 134(41):241-251 (In Polish with English summary)
Radwanek-Bak B (2007) The concept of multi-criteria mineral resources protection. Environ Geol 52:137-145

Rozos D, Bathrellos GD, Skillodimou HD (2011) Comparison of the implementation of rock engineering system and analytic hierarchy process methods, upon landslide susceptibility mapping, using GIS: a case study from the Eastern Achaia County of Peloponnesus, Greece. Environ Earth Sci 63:49-63. doi:10.1007/ s12665-010-0687-z

Saaty TL (1980) The analytic hierarchy process. McGraw-Hill, USA

Saaty RW (1987) The analytic hierarchy process-what it is and how it is used. Math Model 9(3-5):161-176

Saaty TL (2008) Relative measurement and its generalization in decision making why pairwise comparisons are central in mathematics for the measurement of intangible factors the analytic hierarchy/network process. Rev R Acad Cien Ser A Mat 102:251-318. http://www.rac.es/ficheros/doc/00576.PDF. Accessed 03 Dec 2013

Sobczyk E, Badera J (2013) The problem of developing prospective hard coal deposits from the point of view of social and environmental conflicts with the use of AHP method. Miner Res Manag 29(4):5-24. doi:10.2478/gospo-2013-0040

Uberman R (2011) Rating lignite deposits for legal protection of their accessibility for further exploitation. Energy Policy J 14(2):415-425 (In Polish with English summary)

Uberman R, Naworyta W (2012) Lignite exploitation under spatial and environmental restrictions - case study: gubin lignite deposit. Energy Policy J 15(4):29-41 (In Polish with English summary)

Uberman R, Ostręga A (2008) Applying the analytical hierarchy process for the valorisation (ranking) of the polish lignite deposits. Miner Res Manag 24(2/4):73-95 (In Polish with English summary)

Vaidya OS, Kumar S (2006) Analytic hierarchy process: an overview of applications. Eur J Oper Res 169:1-29 